\title{
Influence of low-pulsed frequency on arc profile and weld formation characteristics in double-pulsed VPTIG welding of aluminium alloys
}

\author{
Wang Yipeng ${ }^{1,2}$, Cong Baoqiang ${ }^{* 1}$, Qi Bojin ${ }^{* 1}$, Chen $\mathrm{Xin}^{2}$, Yin Yuhuan ${ }^{3}$, Lin Sanbao ${ }^{4}$ \\ ${ }^{1}$ School of Mechanical Engineering and Automation, Beihang University, Beijing 100191, China \\ ${ }^{2}$ Welding Engineering and Laser Processing Centre, Cranfield University, Cranfield, United Kingdom \\ ${ }^{3}$ Shanghai Aerospace Equipments Manufacturer Co., Ltd., Shanghai 200245, China \\ ${ }^{4}$ Key Lab of Advanced Welding and Joining, Harbin Institute of Technology, Harbin 150001, China \\ *Corresponding authors, email: congbq@buaa.edu.cn, qbj@buaa.edu.cn; Tel/Fax: +86-(0)10-82338722
}

\begin{abstract}
AA2219 aluminium alloy plates were processed by double pulsed variable polarity tungsten inert gas (DP-VPTIG) welding, and the influence of low-pulsed frequency on arc profile, weld appearance and penetration characteristics were investigated. An image processing algorithm was proposed for arc edge extraction and arc feature sizes acquisition. The arc energy equations in low-frequency pulse peak stage $\left(t_{\mathrm{p}}\right)$ and base stage $\left(t_{\mathrm{b}}\right)$ were established based on the electrical parameters. The arc profile periodically expanded in $t_{\mathrm{p}}$ and shrunk in $t_{\mathrm{b}}$, resulted from the difference in arc energy of the two stages. The pulsation effects in arc profile, weld appearance and penetration, caused by the pulsed arc were observed to exhibit a decreasing trend with the increase of low-pulsed frequency $\left(f_{\mathrm{L}}\right)$. The pulsation effects were obvious when $f_{\mathrm{L}}$ was $0.5 \mathrm{~Hz}$, then became weak and tended to disappear as $f_{\mathrm{L}}$ increased above $3 \mathrm{~Hz}$. The empirical correlations between $f_{\mathrm{L}}$ and the pulsation effects of arc profile, weld appearance and penetration were respectively developed. It is recommended to use $f_{\mathrm{L}}$ in the range of $1-2 \mathrm{~Hz}$ to properly exert the low-frequency pulsation effect. The results provide a valuable basis for controlling and optimizing the DP-VPTIG process in the high efficiency welding of aluminum alloys.
\end{abstract}

Keywords: welding arc, double pulses, weld formation, tungsten inert gas welding, aluminium alloy

\section{Introduction}

Aluminium alloys have been extensively applied in the fields of aviation, aerospace and automobile industries owing to their excellent fracture toughness, corrosion resistance and high specific strength [1]. Due to the advantages of cathode cleaning effect on removal of the surface oxide film and high operational flexibility, variable polarity tungsten inert gas (VPTIG) welding process is widely adopted in the welding of aluminium alloys [2]. However, the penetration depth of VPTIG unconstrained welding arc is relatively low caused by the limitation of current-carrying capacity of the non-consumable electrode, which leads to low production efficiency and greatly limits its further application [3]. With the purpose to promote the welding efficiency and satisfy the growing demand for the high-quality TIG welding, investigators have done a large amount of research work, involving the use of mixed shielding gases [4], the application of assistant measures (external magnetic field, ultrasound) [5], the variants of conventional TIG process (A-TIG activated TIG, K-TIG - keyhole TIG, CF-TIG - cathode focused TIG, multiple-electrodes TIG) [6], the introduction of pulsed arc (high-frequency pulse, low-frequency pulse) [7], etc.

Current pulsing achieved by modulating the current waveform of the power source has been considered to be one of the most flexible and effective method to improve the arc properties and weld quality. Yang et al. [8] indicated that the welding arc was distinctly constricted and the arc force was largely enhanced by 
high-frequency pulsed welding $(20 \mathrm{kHz}, 40 \mathrm{kHz})$ in comparison to the conventional TIG welding. Fang et al. [9] experimentally found that the high-frequency pulse (around $40 \mathrm{kHz}$ ) was beneficial to increase the weld penetration and expand the current window in K-TIG welding of Q345 steel plates. Yang et al. [10] demonstrated that compared with conventional TIG welding, the refinement of grain size in weld zone and the improvement of tensile properties were realized by high-frequency pulsed welding with $20 \%$ duty cycle. The low-frequency pulsed current $(1-1.5 \mathrm{~Hz})$ was proved to effectively stabilize the high efficiency welding of 304 stainless steel with a wider current window [11]. The grain structure was refined contributed by the oscillating effect of the arc pressure in $2 \mathrm{~Hz}$ low-frequency pulsed VP-TIG welding [12].

To further improve the welding applicability of VPTIG to aluminium alloy plates, the variable polarity square wave current was simultaneously modulated into high-frequency $(20-80 \mathrm{kHz})$ and low-frequency $(0.5-10 \mathrm{~Hz})$ pulses, referred as DP-VPTIG. The high-frequency pulse was used to enhance the arc penetrating ability, and the low-frequency pulse was used to flexibly adjust the balance of arc heat and force effects to stabilize the weld pool. Stable keyhole mode high penetration welding of $7 \mathrm{~mm}$ thick AA2219 aluminium alloy plate was successfully realized by DP-VPTIG process through properly adjusting the pulse current parameters [13]. Previous work has preliminarily revealed the dynamic evolution processes of the arc profile and weld pool morphology throughout a complete low-frequency pulse period in DP-VPTIG process $[12,14]$. It has been found that low-pulsed frequency was an essential factor for the process stability and weld quality. As welding arc is the heat and force source of the welding process, it is necessary to deeply investigate the arc profile and corresponding weld formation characteristics under the effect of low-pulsed frequency, and explore its potential advantages in weld formation and quality control. In this study, the influence of low-pulsed frequency on arc profile and weld formation characteristics, reflected by weld appearance and weld penetration, in DP-VPTIG welding of AA2219 aluminium alloy plates were investigated.

\section{Methodology}

\subsection{Experimental set-up}

The experimental system for the observation of welding arc is schematically displayed in Fig. 1. This system mainly consisted of a self-developed DP-VPTIG welding power source, a screw motion system, a welding torch and its water cooling system, the shielding gas and an image acquisition system. The acquisition system was primarily composed of a CMOS-based high-speed camera (MS 75K) and a real-time control and recording system on a computer. A close-focusing macro lens (Navitar ZOOM 7000) with a neutral-density filter was installed on the camera. The camera was fixed by the side of the motion system, and its lens focused on the area around the electrode tip. During welding, the welding torch was kept stationary, while the work-piece moved with the motion system. 


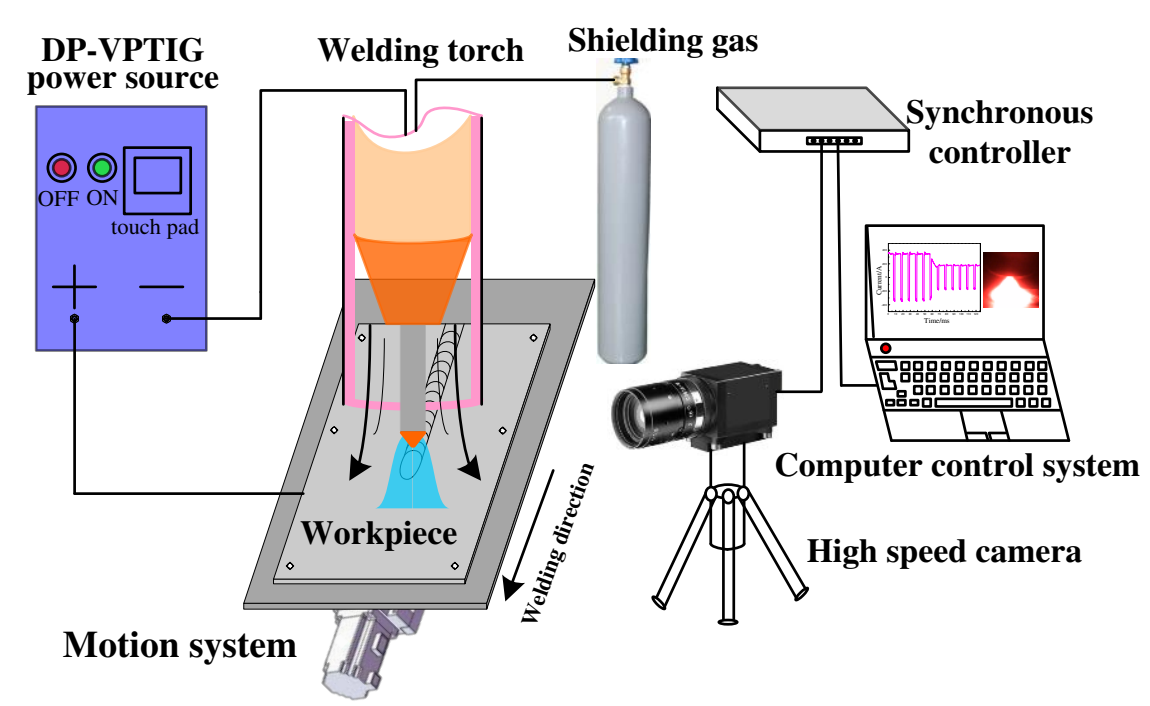

Fig.1 Schematic diagram of the welding system

The schematic diagram of DP-VPTIG current waveform is illustrated in Fig. 2. The variable polarity square wave was modulated into low-frequency pulses $(0.5-10 \mathrm{~Hz})$, and the high-frequency pulses $(20-80$ $\mathrm{kHz}$ ) were superposed onto the positive polarity stage. In the figure, $T_{\mathrm{v}}$ is the period of variable polarity square wave, $t_{\mathrm{vp}}$ is the duration of positive stage, $t_{\mathrm{vn}}$ is the duration of negative stage, $T_{\mathrm{L}}$ is the period of lowfrequency pulse, $t_{\mathrm{p}}$ is the duration of low-frequency pulse peak stage, $t_{\mathrm{b}}$ is the duration of low-frequency pulse base stage, $I_{\mathrm{pp}}$ is the positive current during $t_{\mathrm{p}}, I_{\mathrm{pn}}$ is the negative current during $t_{\mathrm{p}}, I_{\mathrm{bp}}$ is the positive current during $t_{\mathrm{b}}, I_{\mathrm{bn}}$ is the negative current during $t_{\mathrm{b}}, I_{\mathrm{HP}}$ is the amplitude of high-frequency pulse. Limited by the design of the main circuit topology, $I_{\mathrm{pp}}$ and $I_{\mathrm{pn}}, I_{\mathrm{bp}}$ and $I_{\mathrm{bn}}$ couldn't be set separately, namely $I_{\mathrm{pp}}=I_{\mathrm{pn}}$ and $I_{\mathrm{bp}}=I_{\mathrm{bn}}$. To simplify the description in the following discussion, $I_{\mathrm{p}}$ and $I_{\mathrm{b}}$ were used to represent the lowfrequency pulse peak current $\left(I_{\mathrm{pp}} / I_{\mathrm{pn}}\right)$ and base current $\left(I_{\mathrm{bp}} / I_{\mathrm{bn}}\right)$, respectively.

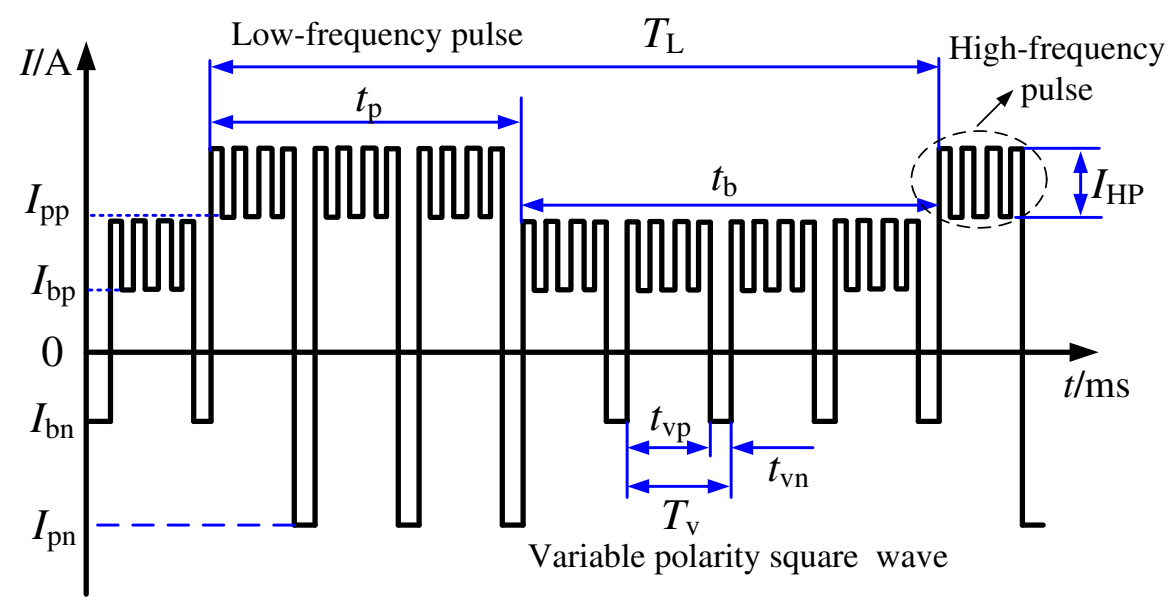

Fig.2 Schematic diagram of DP-VPTIG current waveform

\subsection{Arc edge extraction}

To investigate the arc profile characteristics, it is necessary to first identify and extract the clear arc edge, so as to obtain the appropriate feature sizes for the representation of the arc profile. The arc edge extraction algorithm mainly included the following steps. 

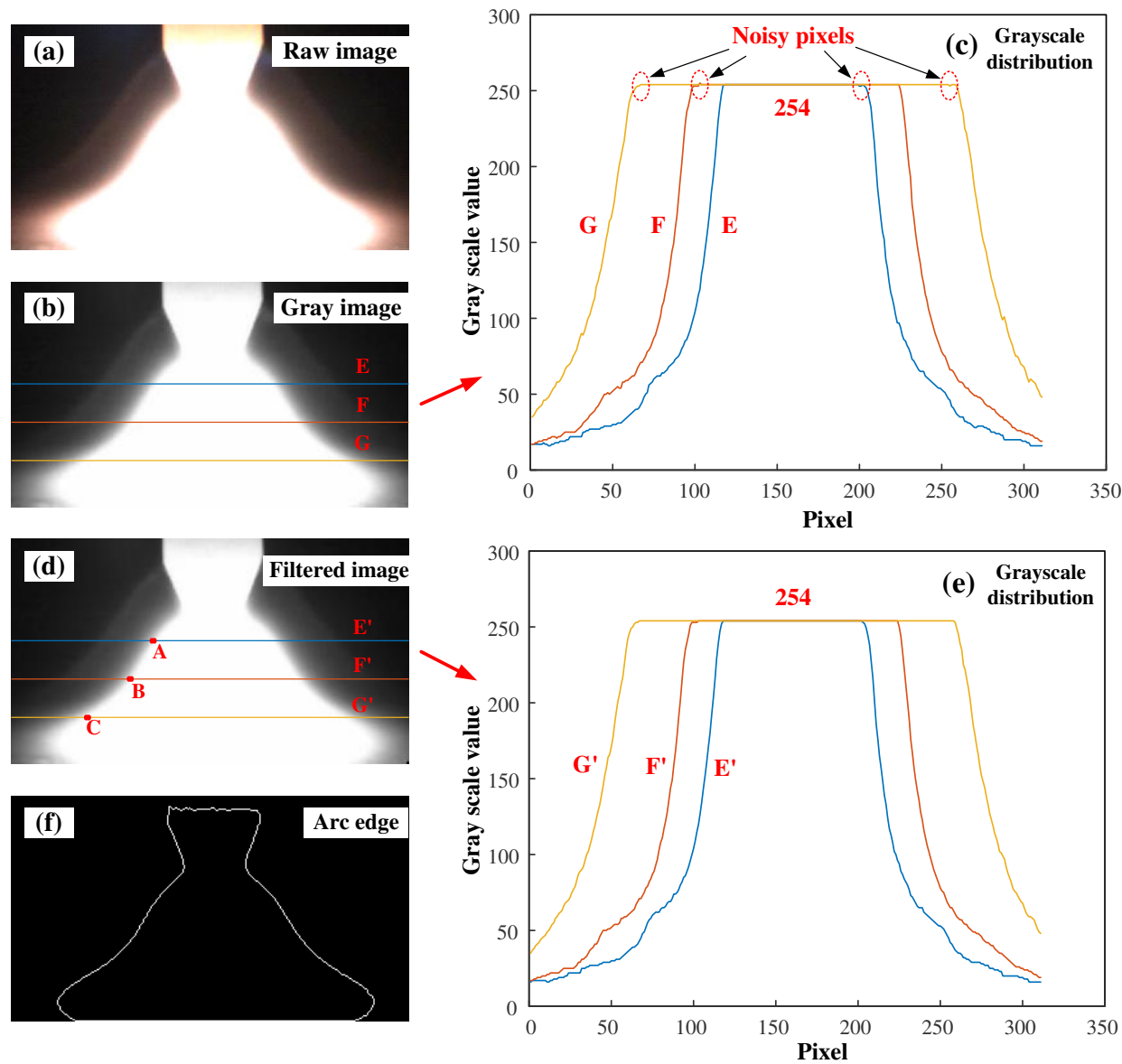

Fig.3 Image processing procedure for arc edge extraction.

(1) Grayscale transformation. The arc raw image (311*176 pixels) displaying in Fig.3a was converted into a 256-level grayscale image, as shown in Fig.3b. In the grayscale image, the light intensity was classified into 256 levels. A higher grayscale value indicated a higher light intensity.

(2) Image de-noising. The grayscale value distribution of the specific lines $\mathrm{E}, \mathrm{F}$ and $\mathrm{G}$ is shown in Fig.3c. It can be found that there were some noisy pixels with grayscale values obviously different from those of the adjacent pixels, which may lead to the misrecognition of the arc edge. To supress these noisy pixels, the median filter with a window size of $3 \times 3$ was employed. The de-noised image and its corresponding grayscale value distribution are illustrated in Fig.3d and Fig.3e, respectively. The noisy pixels were effectively reduced without blurring the edge of the arc.

(3) Arc edge extraction. As displayed in Fig.3e, the image had an obvious contrast between the arc area and the background. The grayscale value rose monotonically as the pixel approached to the arc edge. In the arc central region, the grayscale value became nearly saturated (254), corresponding to the highest light intensity. Here, $95 \%$ of the saturated grayscale value (242) was selected as the threshold value to distinguish the arc edge from the background. The grayscale values were converted into binary values of 1 (higher than threshold value) or 0 
(lower than threshold value). The interior pixels were then removed to leave an outline of the arc shape. The edge extracted image is shown in Fig.3f, in which continuous and clear arc edge was successfully obtained.

\subsection{Arc feature sizes acquisition and calibration}

As shown in Fig.4, the arc projected size $\left(D_{\mathrm{B}}\right)$, arc electrode end size $\left(D_{\mathrm{E}}\right)$ and $\operatorname{arc}$ length $(L)$ were used to reflect the feature sizes of welding arc profile [15]. From the edge extracted image, it is obvious that the arc started to expand from the electrode end, and its radial dimension increased continuously until arriving at the work-piece end. Namely, $D_{\mathrm{E}}$ was exactly the minimum distance between the two edges of the arc along $X$-axis, while $D_{\mathrm{B}}$ was the maximum one. The $\operatorname{arc}$ length $L$ was the distance between the above two lines along $Y$-axis. Based on this point, a calculation and calibration algorithm to automatically acquire the dimensions of $D_{\mathrm{E}}, D_{\mathrm{B}}$ and $L$ was proposed by the following steps.

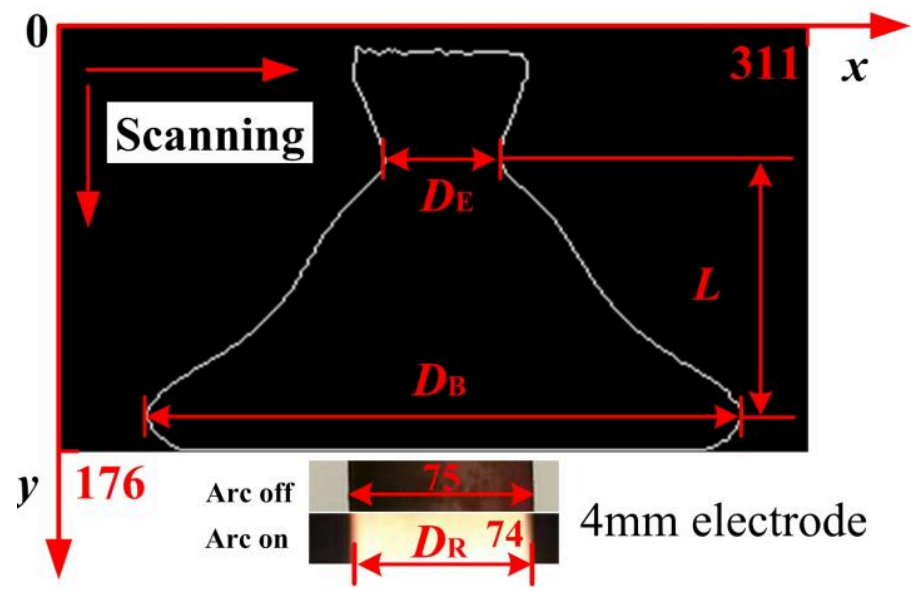

Fig.4 Arc feature sizes acquisition and calibration

(1) Edge detection. The grayscale values of each pixel horizontally along $X$-axis $(X: 0-311, Y=0)$ were point-by-point scanned. The coordinate values were recognized and recorded when the grayscale value was 1 , where the arc edge points in this $X$-axis line were located at. This step were repeated layer-by-layer along $Y$-axis $(Y: 0-176)$ until all the arc edge points were detected.

(2) Dimensions acquisition. The distances between two arc edge points in each horizontal line were calculated. All the distances were then compared with each other, and $D_{\mathrm{E}}, D_{\mathrm{B}}$ as well as $L$ in pixels ( $D_{\mathrm{E}-\text { pixel }}, D_{\mathrm{B}-\text { pixel }}$ and $\left.L_{\text {pixel }}\right)$ were acquired by the above mentioned idea.

(3) Calibration. To calibrate the three parameters from pixels to actual dimensions, the tungsten electrode with diameter of $4 \mathrm{~mm}$ ( $D_{\mathrm{R} \text {-pixel }}$ calculated in pixels) was selected as the reference dimension. As shown in the figure, there was a slight difference in electrode boundary when the arc was burning. The error in the measured value of the electrode diameter between arc burning and arc stop states was around $1 \%$, which was considered acceptable. The calibration expressions were given by Equations 1-3.

$$
\begin{aligned}
& D_{\text {E }}=K \cdot D_{\text {E-pixel }} \\
& D_{\text {B }}=K \cdot D_{\text {B-pixel }}
\end{aligned}
$$




$$
L=K \cdot L_{\text {pixel }}
$$

where $K=4 / D_{\text {R-pixel. }}$

\subsection{Process parameters}

Bead-on-plate welding trials were carried out on $7 \mathrm{~mm}$ thick AA2219 aluminium alloy plates. To remove the impurities such as grease, oxide film and stains on the surface of the plates, the work-pieces were sequentially washed with alkaline water $\left(\mathrm{NaOH} 10 \%\right.$ and $\left.\mathrm{H}_{2} \mathrm{O} 90 \%\right)$ and acid water $\left(\mathrm{HNO}_{3} 15 \%\right.$ and $\mathrm{H}_{2} \mathrm{O} 85 \%$, all in volume fraction), and then cleaned with industrial alcohol and dried in air prior to welding. The shielding gas used was pure argon with a flow rate of $15 \mathrm{~L} \cdot \mathrm{min}^{-1}$. The electrode adopted was a cerium-tungsten with a diameter of $4 \mathrm{~mm}$, and the cone angle of its front tip was 30 degrees. The welding speed was $170 \mathrm{~mm} \cdot \mathrm{min}^{-1}$. Six low-pulsed frequencies were used for the observation of arc profile, and the low-frequency pulse parameters are listed in Table 1. Other current parameters were $T_{\mathrm{v}}$ $=10 \mathrm{~ms}, t_{\mathrm{vp}}: t_{\mathrm{vn}}=8: 2, I_{\mathrm{HP}}=80 \mathrm{~A}$, pulse frequency $f_{\mathrm{HP}}=20 \mathrm{kHz}$, duty cycle $\delta_{\mathrm{HP}}=50 \%$. The sampling frequency of the high-speed camera was 2000 frames per second, and the exposure time was 100 microseconds. The lens aperture of the camera was 5.6. As experimentally observed by Wang et al. [12], the arc profile gradually became stable when the current was switched from $t_{\mathrm{vn}}$ to $t_{\mathrm{vp}}$ throughout the variable polarity period. To ensure the consistency of the results, the arc images were all captured from $t_{\mathrm{vp}}$ at the same transient when they became stable.

Table 1. The welding parameters

\begin{tabular}{ccccc}
\hline Test No. & $f_{\mathrm{L}} / \mathrm{Hz}$ & $I_{\mathrm{p}} / \mathrm{A}$ & $I_{\mathrm{b}} / \mathrm{A}$ & $\delta / \%$ \\
\hline 1 & 0.5 & 240 & 100 & 50 \\
2 & 1 & 240 & 100 & 50 \\
3 & 2 & 240 & 100 & 50 \\
4 & 3 & 240 & 100 & 50 \\
5 & 5 & 240 & 100 & 50 \\
6 & 10 & 240 & 100 & 50 \\
\hline
\end{tabular}

\section{Results and discussion}

\subsection{Arc profile variation between $t_{\mathrm{p}}$ and $t_{\mathrm{b}}$}

The arc images in $t_{\mathrm{p}}$ and $t_{\mathrm{b}}$ at low-pulsed frequency $0.5 \mathrm{~Hz}$ are displayed in Fig.5. Table 2 lists the sizes of arc projected size $D_{\mathrm{B}}$, arc electrode end size $D_{\mathrm{E}}$ and arc length $L$ of the corresponding arc images. In $t_{\mathrm{p}}$, the arc profile was largely expanded due to the high current value. $D_{\mathrm{B}}, D_{\mathrm{E}}$ and $L$ were $17.0 \mathrm{~mm}, 3.3 \mathrm{~mm}$ and $6.3 \mathrm{~mm}$, respectively. As welding current switched to $t_{\mathrm{b}}$, the arc profile shrunk sharply because of the significant reduction in current value. The consequential sizes of $D_{\mathrm{B}}, D_{\mathrm{E}}$, and $L$ reduced to $9.9 \mathrm{~mm}, 2.4 \mathrm{~mm}$ and $6.1 \mathrm{~mm}$, respectively. The size of $D_{\mathrm{B}}$, which directly acted on the surface of weld pool, changed most obviously $(7.1 \mathrm{~mm})$, while the changes of $D_{\mathrm{E}}$ and $L$ were relatively small $(0.9 \mathrm{~mm}$ and $0.2 \mathrm{~mm})$ due to the restriction of the tungsten electrode tip. 

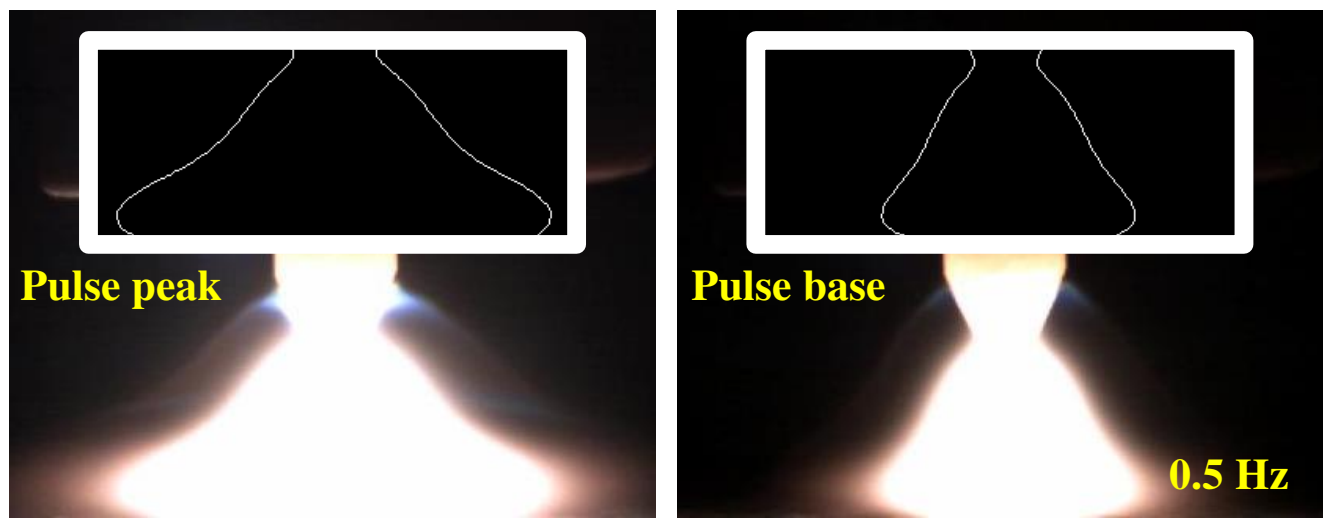

Fig.5 Arc images in $t_{\mathrm{p}}$ and $t_{\mathrm{b}}\left(f_{\mathrm{L}}=0.5 \mathrm{~Hz}\right)$

Table 2 Sizes of $D_{\mathrm{B}}, D_{\mathrm{E}}$ and $L$ in $t_{\mathrm{p}}$ and $t_{\mathrm{b}}\left(f_{\mathrm{L}}=0.5 \mathrm{~Hz}\right)$

$\begin{array}{cccc}\text { Stage }_{t_{\mathrm{p}}}^{\text {Size }} & D_{\mathrm{B}} / \mathrm{mm} & D_{\mathrm{E}} / \mathrm{mm} & L / \mathrm{mm} \\ t_{\mathrm{b}} & 17.0 & 3.3 & 6.3 \\ & 9.9 & 2.4 & 6.1\end{array}$

It is known that the arc profile is a reflection of arc light energy, which is converted from the electric energy provided by the welding power source. Therefore, the variation in arc profile between $t_{\mathrm{p}}$ and $t_{\mathrm{b}}$ can be explained by the electrical characteristics of DP-VPTIG process. The current waveform with pulse frequency $0.5 \mathrm{~Hz}$ is shown in Fig.6. It can be observed that there were plenty of variable polarity square waves in both $t_{\mathrm{p}}$ and $t_{\mathrm{b}}$. The high-frequency pulses were superimposed onto the positive stage in each variable polarity period. Due to the difference in amplitude value between $t_{\mathrm{p}}$ and $t_{\mathrm{b}}$, the energy pulsation would occur when the current switched between the two stages. The arc light energy generated in $t_{\mathrm{p}}$ and $t_{\mathrm{b}}$ can be expressed by Equations 4 and 5, respectively.

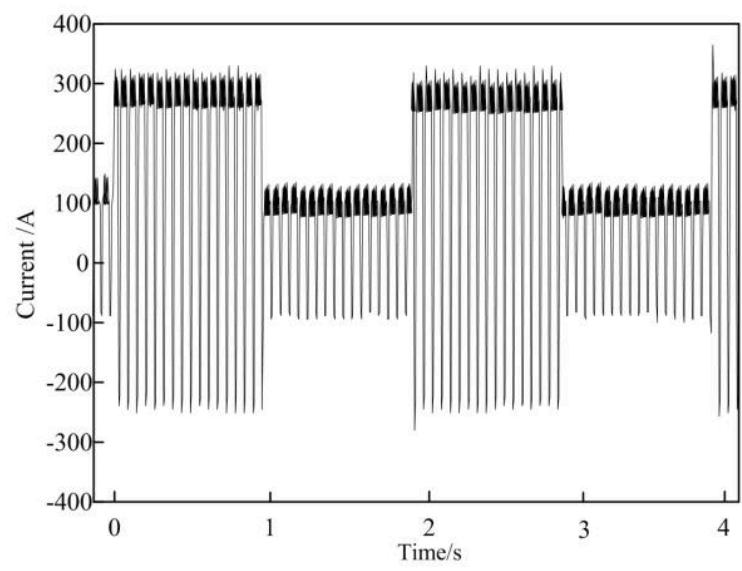

Fig.6 Current waveform of DP-VPTIG $(f \mathrm{~L}=0.5 \mathrm{~Hz})$

$$
\begin{aligned}
Q_{\mathrm{p}} & =\eta_{\mathrm{ARC}} \cdot \int_{0}^{t_{\mathrm{p}}} u_{\mathrm{t}} i_{\mathrm{t}} \mathrm{d} t \\
& =\eta_{\mathrm{ARC}} \cdot \frac{f_{\mathrm{v}}}{f_{\mathrm{L}}} \cdot \delta \cdot\left[\int_{0}^{t_{\mathrm{pp}}} u_{\mathrm{t}} i_{\mathrm{t}} \mathrm{d} t+\int_{\mathrm{vp}}^{t_{\mathrm{vp}}} u_{\mathrm{t}} i_{\mathrm{t}} \mathrm{d} t\right] \\
& =\eta_{\mathrm{ARC}} \cdot \frac{f_{\mathrm{v}}}{f_{\mathrm{L}}} \cdot \delta \cdot\left[\left(I_{\mathrm{pp}}+I_{\mathrm{HP}-\text { avg }}\right) U_{\mathrm{pp}}+I_{\mathrm{pn}} U_{\mathrm{pn}}\right]
\end{aligned}
$$




$$
\begin{aligned}
Q_{\mathrm{b}} & =\eta_{\mathrm{ARC}} \cdot \int_{t_{\mathrm{p}}}^{t_{\mathrm{b}}} u_{\mathrm{t}} i_{\mathrm{t}} \mathrm{d} t \\
& =\eta_{\mathrm{ARC}} \cdot \frac{f_{\mathrm{v}}}{f_{\mathrm{L}}} \cdot(1-\delta) \cdot\left[\int_{0}^{t_{\mathrm{pp}}} u_{\mathrm{t}} i_{\mathrm{t}} \mathrm{d} t+\int_{t_{\mathrm{vp}}}^{t_{\mathrm{wn}}} u_{\mathrm{t}} i_{\mathrm{t}} \mathrm{d} t\right] \\
& =\eta_{\mathrm{ARC}} \cdot \frac{f_{\mathrm{v}}}{f_{\mathrm{L}}} \cdot(1-\delta) \cdot\left[\left(I_{\mathrm{bp}}+I_{\mathrm{HP}-\text { avg }}\right) U_{\mathrm{bp}}+I_{\mathrm{bn}} U_{\mathrm{bn}}\right]
\end{aligned}
$$

Where $Q_{\mathrm{p}}$ is the light energy in $t_{\mathrm{p}}, Q_{\mathrm{b}}$ is the light energy in $t_{\mathrm{b}}, \eta_{\mathrm{ARC}}$ is the conversion rate from electric energy to light energy, $u_{\mathrm{t}}$ is the transient voltage, $i_{\mathrm{t}}$ is the transient current, $I_{\mathrm{HP}-\mathrm{avg}}=I_{\mathrm{HP}} \times \delta_{\mathrm{HP}}$ is the average value of high-frequency current, $U_{\mathrm{pp}}$ is the positive voltage in $t_{\mathrm{p}}, U_{\mathrm{pn}}$ is the negative voltage in $t_{\mathrm{p}}, U_{\mathrm{bp}}$ is the positive voltage in $t_{\mathrm{b}}, U_{\mathrm{bn}}$ is the negative voltage in $t_{\mathrm{b}}$.

According to Equations 4 and 5, the arc light energy generated in $t_{\mathrm{p}}\left(Q_{\mathrm{p}}\right)$ and $t_{\mathrm{b}}\left(Q_{\mathrm{b}}\right)$ are determined by the electrical parameters of low-frequency pulse, high-frequency pulse and variable polarity square wave. In the case where current parameters of high-frequency pulse and variable polarity square wave remain constant, $Q_{\mathrm{p}}$ and $Q_{\mathrm{b}}$ are primarily affected by low-frequency pulse parameters. In the experimental condition, the amplitude value of $I_{\mathrm{p}}(240 \mathrm{~A})$ is much higher than that of $I_{\mathrm{b}}(100 \mathrm{~A})$, which means that the arc light energy in $t_{\mathrm{p}}$ is more than two times higher than that in $t_{\mathrm{b}}$. Therefore, the arc profile variation between $t_{\mathrm{p}}$ and $t_{\mathrm{b}}$ are principally resulted from the large difference in arc light energy.

\subsection{Effects of low-pulsed frequency on arc profile}

\section{Arc profile in $t_{\mathrm{p}}$}

The arc images and their corresponding feature sizes in low-frequency pulse peak stage at different $f_{\mathrm{L}}$ are shown in Fig.7a and Fig.7b, respectively. It can be seen that the size of $D_{\mathrm{B}}$ varied most significantly with $f_{\mathrm{L}}$ compared to those of $D_{\mathrm{E}}$ and $L . D_{\mathrm{B}}$ decreased monotonously with increasing $f_{\mathrm{L}}$. When $f_{\mathrm{L}}$ changed from 0.5 to $3 \mathrm{~Hz}$, the drop rate of $D_{\mathrm{B}}$ was relatively high, with its size falling down rapidly from $17.0 \mathrm{~mm}$ to $16.1 \mathrm{~mm}$. As $f_{\mathrm{L}}$ further increased to the level higher than $3 \mathrm{~Hz}$, the drop rate of $D_{\mathrm{B}}$ gradually became smaller, and its size slowly stabilized at around $15.5 \mathrm{~mm}$. The arc electrode end size $D_{\mathrm{E}}$ presented a similar variation trend to that of $D_{\mathrm{B}}$, but due to the restriction of the tungsten electrode, its changes with $f_{\mathrm{L}}$ were much smaller. $D_{\mathrm{E}}$ dropped from $3.3 \mathrm{~mm}$ to $3.0 \mathrm{~mm}$ as $f_{\mathrm{L}}$ varied from $0.5 \mathrm{~Hz}$ to $3 \mathrm{~Hz}$. Then it decreased slowly to about $2.9 \mathrm{~mm}$ at $10 \mathrm{~Hz}$. The arc length $L$ showed an increasing trend with $f_{\mathrm{L}}$. When $f_{\mathrm{L}}$ varied from 0.5 to $1 \mathrm{~Hz}$, the size of $L$ increased from $6.3 \mathrm{~mm}$ to $6.7 \mathrm{~mm}$ with a relatively high rising rate. It then fluctuated slightly between 6.6 $\mathrm{mm}$ and $6.7 \mathrm{~mm}$ as $f_{\mathrm{L}}$ further increased. In $t_{\mathrm{p}}$, the arc profile shrunk, representing that $D_{\mathrm{B}}$ and $D_{\mathrm{E}}$ decreased and $L$ increased, as $f_{\mathrm{L}}$ increased. 

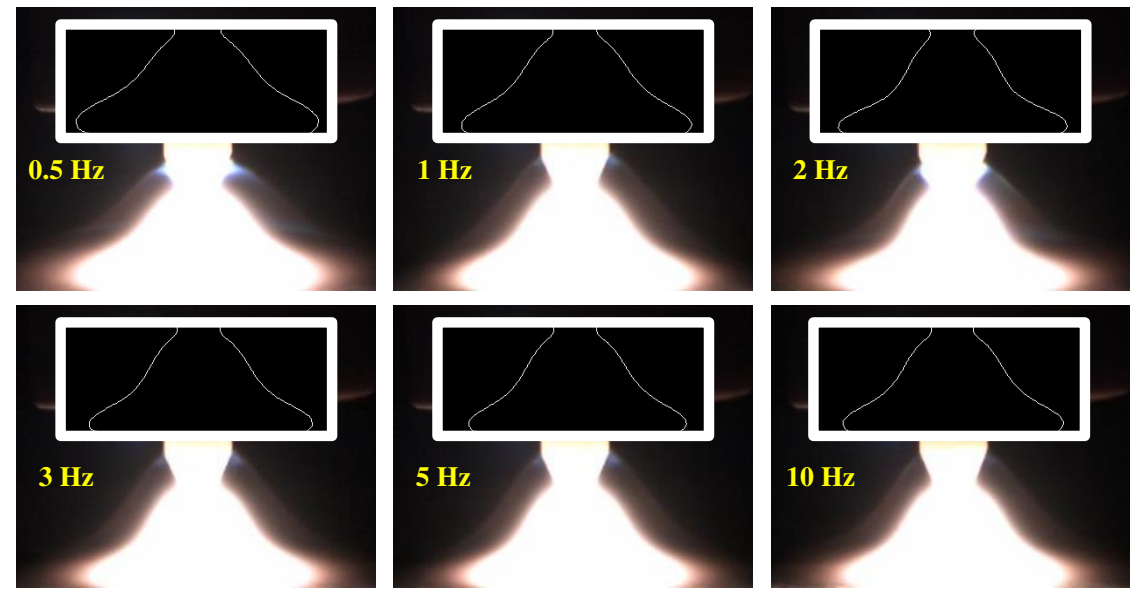

(a) Arc images

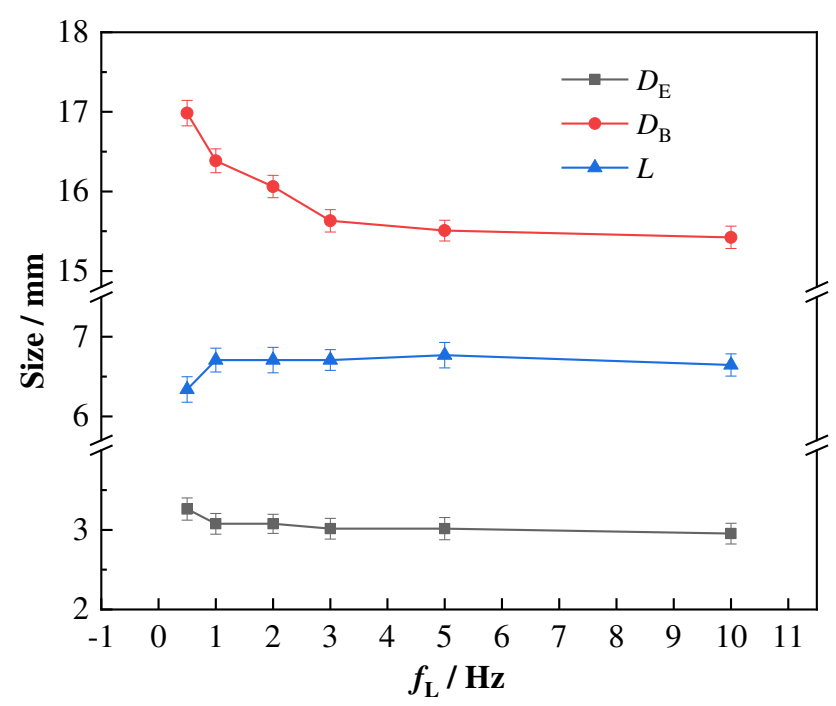

(b) Sizes of $D_{\mathrm{B}}, D_{\mathrm{E}}$ and $L$

Fig.7 Arc images, sizes of $D_{\mathrm{B}}, D_{\mathrm{E}}$ and $L$ in $t_{\mathrm{p}}$ at different $f_{\mathrm{L}}$

Arc profile in $t_{\mathrm{b}}$

Fig. $8 \mathrm{a}$ and Fig. $8 \mathrm{~b}$ illustrate the arc images and their corresponding feature sizes in low-frequency pulse base stage at different $f_{\mathrm{L}}$, respectively. From the figure, the changing trends of $D_{\mathrm{B}}, D_{\mathrm{E}}$ and $L$ with $f_{\mathrm{L}}$ were all completely opposite to those in $t_{\mathrm{p}}$, while the variations of $D_{\mathrm{B}}, D_{\mathrm{E}}$ and $L$ were roughly similar. When $f_{\mathrm{L}}$ increased from 0.5 to $3 \mathrm{~Hz}, D_{\mathrm{B}}$ and $D_{\mathrm{E}}$ rose from $9.9 \mathrm{~mm}$ and $2.4 \mathrm{~mm}$ to $10.9 \mathrm{~mm}$ and $2.5 \mathrm{~mm}$, respectively. They then gradually stabilized at around $11.3 \mathrm{~mm}$ and $2.6 \mathrm{~mm}$ as $f_{\mathrm{L}}$ increased to $10 \mathrm{~Hz}$. $L$ was $6.1 \mathrm{~mm}$ when $f_{\mathrm{L}}$ was $0.5 \mathrm{~Hz}$. It decreased slightly and fluctuated between $6.0 \mathrm{~mm}$ and $5.9 \mathrm{~mm}$ as $f_{\mathrm{L}}$ further increased. In $t_{\mathrm{b}}$, the arc profile expanded, showing that $D_{\mathrm{B}}$ and $D_{\mathrm{E}}$ increased and $L$ decreased, with the increased of $f_{\mathrm{L}}$. 

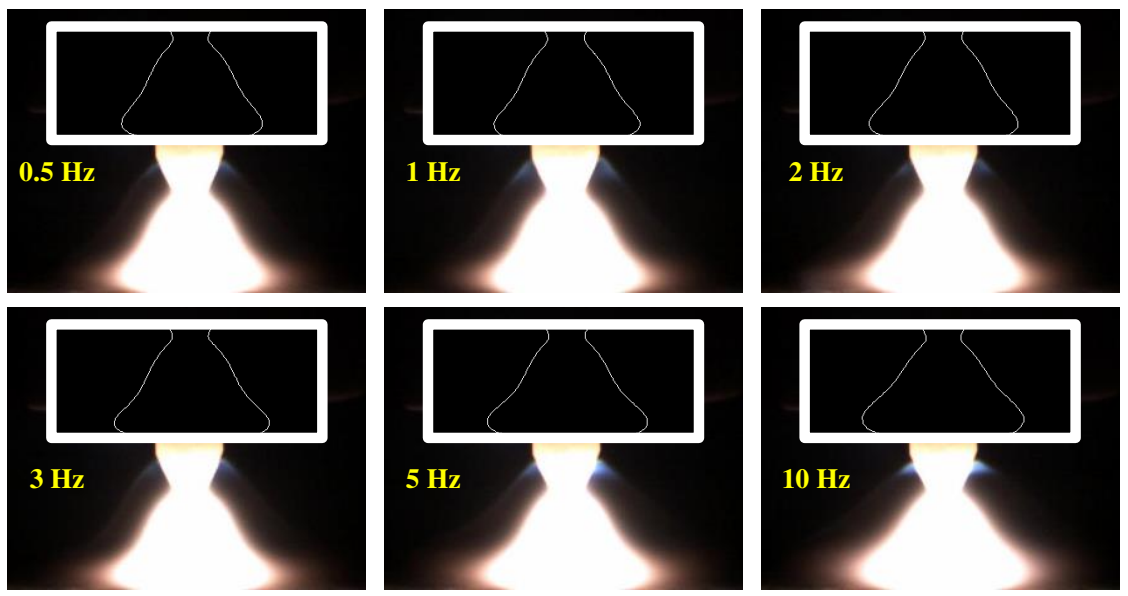

(a) Arc images

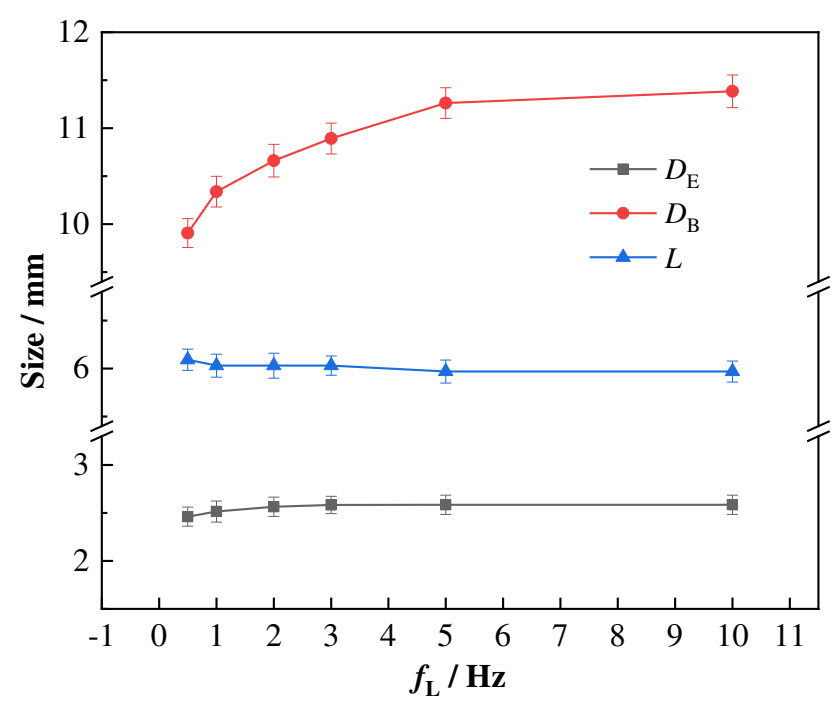

(b) Sizes of $D_{\mathrm{B}}, D_{\mathrm{E}}$ and $L$

Fig.8 Arc images, sizes of $D_{\mathrm{B}}, D_{\mathrm{E}}$ and $L$ in $t_{\mathrm{b}}$ at different $f_{\mathrm{L}}$

Arc profile pulsation between $t_{\mathrm{p}}$ and $t_{\mathrm{b}}$

The differences of $D_{\mathrm{B}}, D_{\mathrm{E}}$ and $L$ between $t_{\mathrm{p}}$ and $t_{\mathrm{b}}\left(\Delta D_{\mathrm{B}}, \Delta D_{\mathrm{E}}\right.$ and $\left.\Delta L\right)$ were defined to represent the pulsation effect of arc profile. $\Delta D_{\mathrm{B}}, \Delta D_{\mathrm{E}}$ and $\Delta L$ at different low-pulsed frequency were calculated and shown in Fig.9. It can be seen that with the increase of $f_{\mathrm{L}}$, the variation of $\Delta D_{\mathrm{B}}$ was most obvious, and the variations of $\Delta D_{\mathrm{E}}$ and $\Delta L$ were relatively small. $\Delta D_{\mathrm{B}}$ and $\Delta D_{\mathrm{E}}$ decreased, while $\Delta L$ increased with increasing $f_{\mathrm{L}}$. As $f_{\mathrm{L}}$ changed from 0.5 to $3 \mathrm{~Hz}, \Delta D_{\mathrm{B}}$ and $\Delta D_{\mathrm{E}}$ fell down from $7.1 \mathrm{~mm}$ and $0.8 \mathrm{~mm}$ to $4.7 \mathrm{~mm}$ and 0.4 $\mathrm{mm}$, respectively. They then gradually decreased to $4.0 \mathrm{~mm}$ and $0.3 \mathrm{~mm}$, respectively, as $f_{\mathrm{L}}$ increased to 10 Hz. $\Delta L$ increased from $0.3 \mathrm{~mm}$ to $0.7 \mathrm{~mm}$ when $f_{\mathrm{L}}$ varied from 0.5 to $1 \mathrm{~Hz}$. It then fluctuated within a small range, less than $0.1 \mathrm{~mm}$, as $f_{\mathrm{L}}$ further increased. In a word, the pulsation effect of arc profile decreased with increasing $f_{\mathrm{L}}$. Based on the experimental results, empirical correlations between $f_{\mathrm{L}}$ and $\Delta D_{\mathrm{B}}, \Delta D_{\mathrm{E}}$ as well as $\Delta L$ were respectively established through polynomial fitting, which can be expressed by Equations 6-8.

$$
\begin{array}{ll}
\Delta D_{\mathrm{B}}\left(f_{\mathrm{L}}\right)=-0.0132 f_{\mathrm{L}}^{3}+0.2624 f_{\mathrm{L}}^{2}-1.6681 f_{\mathrm{L}}+7.7051 & \mathrm{R}^{2}=0.9871 \\
\Delta D_{\mathrm{E}}\left(f_{\mathrm{L}}\right)=-0.0038 f_{\mathrm{L}}^{3}+0.0641 f_{\mathrm{L}}^{2}-0.3181 f_{\mathrm{L}}+0.8972 & \mathrm{R}^{2}=0.9242
\end{array}
$$




$$
\Delta L\left(f_{\mathrm{L}}\right)=0.0036 f_{\mathrm{L}}^{3}-0.0665 f_{\mathrm{L}}^{2}+0.3548 f_{\mathrm{L}}+0.2056 \quad \mathrm{R}^{2}=0.6952
$$

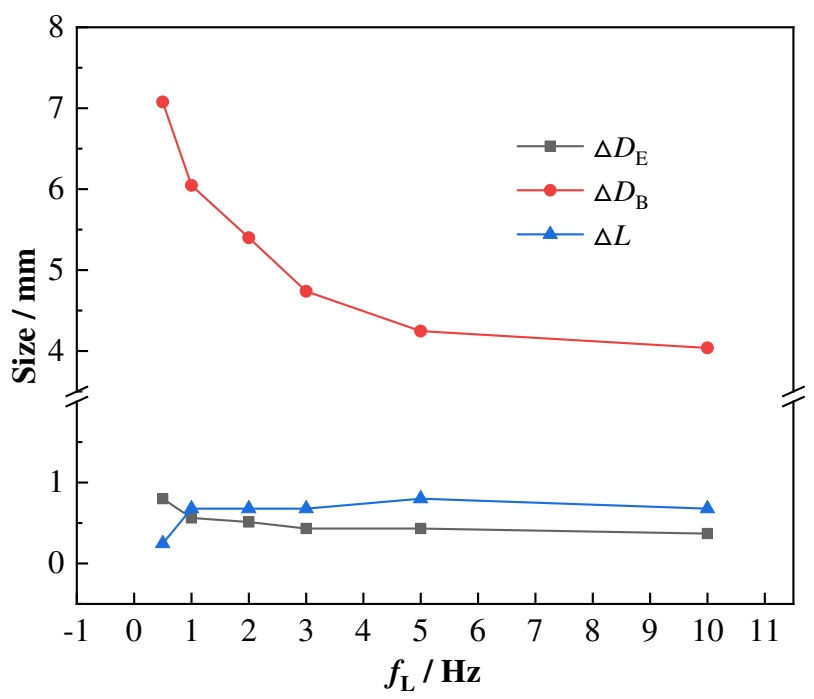

Fig.9 $\Delta D_{\mathrm{B}}, \Delta D_{\mathrm{E}}$ and $\Delta L$ at different $f_{\mathrm{L}}$

The variation in arc profile with $f_{\mathrm{L}}$ could be interpreted by the difference of light energy in $t_{\mathrm{p}}\left(Q_{\mathrm{p}}\right)$ and $t_{\mathrm{b}}\left(Q_{\mathrm{b}}\right)$, which is defined as light energy pulsation effect $(\Delta Q) . \Delta Q$ is given by Equation 9 .

$$
\begin{aligned}
\Delta Q & =Q_{\mathrm{p}}-Q_{\mathrm{b}} \\
& =\eta_{\mathrm{ARC}} \cdot \frac{f_{\mathrm{v}}}{f_{\mathrm{L}}} \cdot\left\{\left[\left(I_{\mathrm{pp}}+I_{\mathrm{HP}-\mathrm{avg}}\right) U_{\mathrm{pp}}+I_{\mathrm{pn}} U_{\mathrm{pn}}\right] \cdot \delta-\left[\left(I_{\mathrm{bp}}+I_{\mathrm{HP}-\mathrm{avg}}\right) U_{\mathrm{bp}}+I_{\mathrm{bn}} U_{\mathrm{bn}}\right] \cdot(1-\delta)\right\}
\end{aligned}
$$

From the Equation 9, it is found that the light energy pulsation between $t_{\mathrm{p}}$ and $t_{\mathrm{b}}$ is inversely proportional to $f_{\mathrm{L}}$. Namely $\Delta Q$, which determines the difference in arc profile between $t_{\mathrm{p}}$ and $t_{\mathrm{b}}$, decreases linearly with the increase of $f_{\mathrm{L}}$. As the other process parameters remain constant, the arc profile thereby exhibits a shrinking trend in $t_{\mathrm{p}}$ and an expanding trend in $t_{\mathrm{b}}$. Therefore, the low-frequency pulsation effect of arc profile decreased with increasing $f_{\mathrm{L}}$.

\subsection{Effects of low-pulsed frequency on weld formation}

As the heat and force source in the welding process, the welding arc directly acts on the heat and mass transfer process inside the weld pool, and ultimately determines the formation characteristics and quality of the weld bead. During DP-VPTIG welding process, in $t_{\mathrm{p}}$, the expanded arc with higher heat and force effect induced a wider weld pool width and a higher penetration depth with obvious depressed deformation of the weld pool surface, as shown in Fig.10a. In $t_{\mathrm{b}}$, the shrunk arc profile with lower heat and force effect led to a narrower weld pool width and a lower penetration depth with the disappearance of the depressed deformation of the weld pool surface, as revealed in Fig.10b. Consequently, under the influence of the periodic variation in arc profile, the pulsation effect of weld formation in both surface appearance and penetration depth was formed. Since the pulsation effect became nearly indistinguishable when $f_{\mathrm{L}}$ was higher than $3 \mathrm{~Hz}$, Tests 1-4 $\left(f_{\mathrm{L}}=0.5-3 \mathrm{~Hz}\right)$ were carried out for the analysis of weld formation characteristics. 

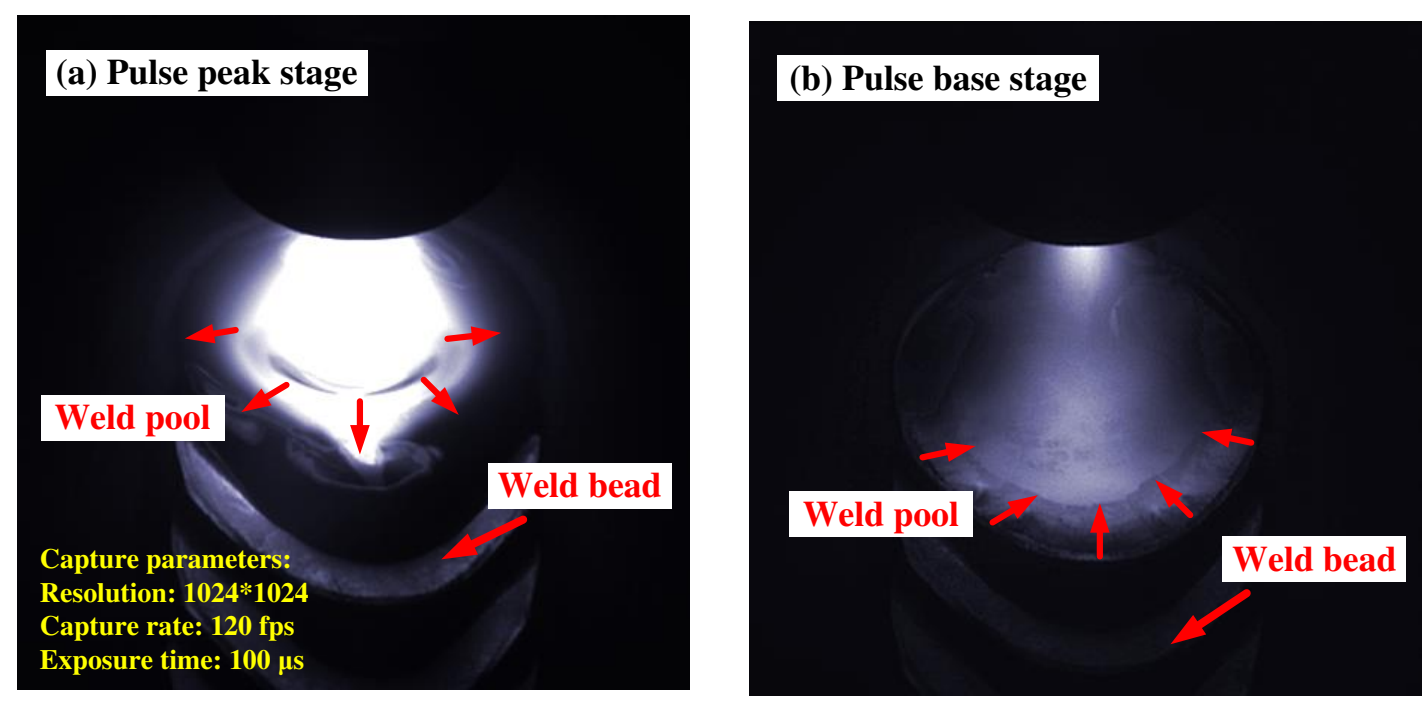

Fig.10 Weld pool morphology in $t_{\mathrm{p}}$ and $t_{\mathrm{b}}\left(f_{\mathrm{L}}=0.5 \mathrm{~Hz}\right)$

\section{Weld appearance}

The weld surface appearances at different $f_{\mathrm{L}}$ are displayed in Fig.11a. The fish-scale ripple shaped weld surface formed due to the pulsation effect of arc profile. As shown in the figure at $0.5 \mathrm{~Hz}$, the weld fish-scale ripple characteristics, namely the pulsation effect of weld appearance, was studied by fish-scale ripple spacing $L_{\mathrm{r}}$ and the difference of fish-scale ripple width $\Delta W\left(\Delta W=W_{\mathrm{p}}-W_{\mathrm{b}}\right)$. Fig.11b illustrates the sizes of $L_{\mathrm{r}}$ and $\Delta W$ versus $f_{\mathrm{L}}$. It can be seen that both $\Delta W$ and $L_{\mathrm{r}}$ decreased monotonously with the increase of $f_{\mathrm{L}}$. When $f_{\mathrm{L}}$ was $0.5 \mathrm{~Hz}$, the size of $L_{\mathrm{r}}$ was $8 \mathrm{~mm}$ and $\Delta W$ was $2.4 \mathrm{~mm}\left(W_{\mathrm{p}}=15.1 \mathrm{~mm}, W_{\mathrm{b}}=12.7 \mathrm{~mm}\right)$, and obvious fishscale ripple characteristics could be observed. As $f_{\mathrm{L}}$ increased, $\Delta W$ and $L_{\mathrm{r}}$ reduced at a smaller drop rate. The size of $L_{\mathrm{r}}$ was $1.4 \mathrm{~mm}$ and $\Delta W$ was $0.3 \mathrm{~mm}\left(W_{\mathrm{p}}=12.0 \mathrm{~mm}, W_{\mathrm{b}}=11.7 \mathrm{~mm}\right)$, and the fish-scale ripple characteristics became quite weak when $f_{\mathrm{L}}$ was $3 \mathrm{~Hz}$. According to the experimental results, $L_{\mathrm{r}}$ and $\Delta W$ as a function of low-pulsed frequency $f_{\mathrm{L}}$ were empirically correlated, as given by Equations 10 and 11 .

$$
\begin{array}{ll}
L_{\mathrm{r}}\left(f_{\mathrm{L}}\right)=-1.3133 f_{\mathrm{L}}^{3}+8.5492 f_{\mathrm{L}}^{2}-18.449 f_{\mathrm{L}}+15.284 & \mathrm{R}^{2}=1 \\
\Delta W\left(f_{\mathrm{L}}\right)=-0.2204 f_{\mathrm{L}}^{3}+1.5546 f_{\mathrm{L}}^{2}-3.8588 f_{\mathrm{L}}+3.918 & \mathrm{R}^{2}=1
\end{array}
$$

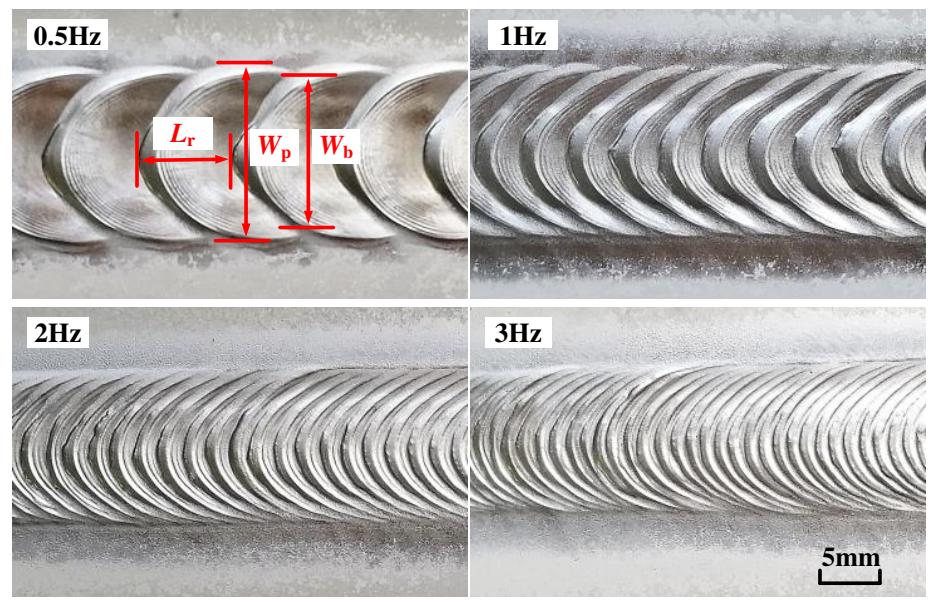

(a) Weld appearance 


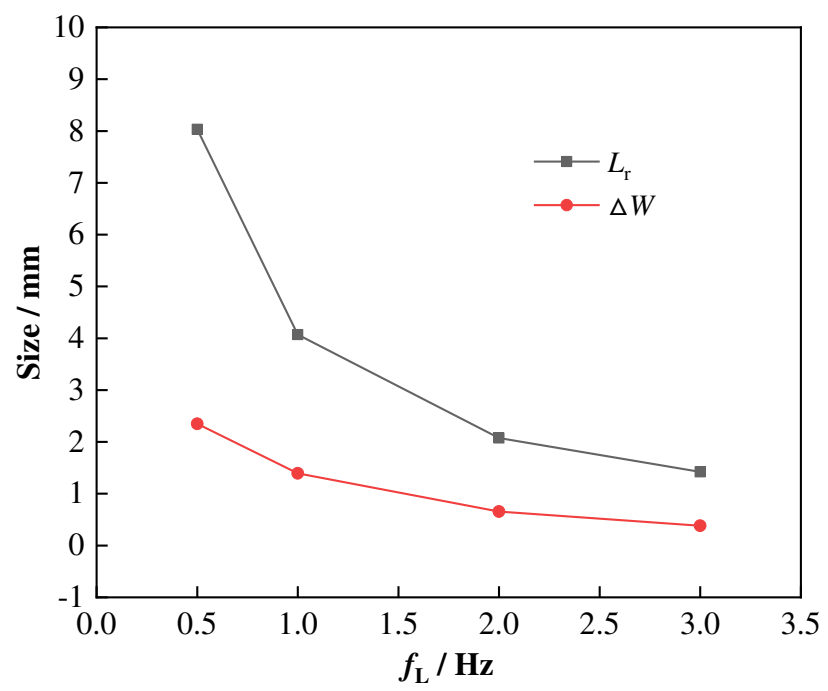

(b) Sizes of $L_{\mathrm{r}}$ and $\Delta W$

Fig.11 Weld appearance, sizes of $L_{\mathrm{r}}$ and $\Delta W$ versus $f_{\mathrm{L}}$

\section{Weld penetration}

Fig.12a shows the macrograph of weld longitudinal section at different $f_{\mathrm{L}}$. The weld penetration profile exhibited a fluctuating characteristic with the low-frequency pulse period. In $t_{\mathrm{p}}$, the penetration $D_{\mathrm{p}}$ was high due to the strong arc heat and force effect, while in $t_{\mathrm{b}}$ the penetration $D_{\mathrm{b}}$ was relatively low caused by the reduction in current amplitude. The pulsation effect of weld penetration was characterised by the difference of penetration $\Delta D\left(\Delta D=D_{\mathrm{p}}-D_{\mathrm{b}}\right)$ between $t_{\mathrm{p}}$ and $t_{\mathrm{b}}$. The sizes of $\Delta D, D_{\mathrm{p}}$ and $D_{\mathrm{b}}$ with different $f_{\mathrm{L}}$ are shown in Fig.12b. With the similar changing trend to those of $L_{\mathrm{r}}$ and $\Delta W$, the size of $\Delta D$ decreased monotonously with increasing $f_{\mathrm{L}} . \Delta D$ was $0.9 \mathrm{~mm}\left(D_{\mathrm{p}}=3.4 \mathrm{~mm}, D_{\mathrm{b}}=2.5 \mathrm{~mm}\right)$ when $f_{\mathrm{L}}$ was $0.5 \mathrm{~Hz}$, and the fluctuation in weld penetration between $t_{\mathrm{p}}$ and $t_{\mathrm{b}}$ was very significant. As $f_{\mathrm{L}}$ increased to $3 \mathrm{~Hz}$, the size of $\Delta D$ reduced to less than $0.2 \mathrm{~mm}\left(D_{\mathrm{p}}=3.4 \mathrm{~mm}, D_{\mathrm{b}}=3.2 \mathrm{~mm}\right)$, meaning that the pulsation effect in weld penetration between $t_{\mathrm{p}}$ and $t_{\mathrm{b}}$ almost disappeared, which was consistent with the pulsation effect of weld appearance and arc profile.

The correlation between $\Delta D$ and $f_{\mathrm{L}}$ can be empirically expressed by polynomial fitting Equation 12 , based on the experimental results. It can be inferred that the pulsation effect in arc profile, weld appearance and penetration with respect to low-pulsed frequency can be distinctly controlled by following the empirical equations.

$$
\Delta D\left(f_{\mathrm{L}}\right)=-0.1 f_{\mathrm{L}}^{3}+0.6652 f_{\mathrm{L}}^{2}-1.5402 f_{\mathrm{L}}+1.513 \quad \mathrm{R}^{2}=1
$$

Owing to the low-frequency pulsation effect, in $t_{\mathrm{p}}$, the high current value could increase the arc penetrating ability to obtain the desired penetration depth, and in $t_{\mathrm{b}}$ the overall heat input could be reduced due to the reduction in current value. It is flexible to balance the arc heat and force effect through adjusting the low-frequency pulse parameters [13]. From the above results, when low-pulsed frequency $f_{\mathrm{L}}$ is less than $0.5 \mathrm{~Hz}$, the arc pulsation effect is so strong that makes the weld formation significantly discontinuous, thereby largely reducing the effective weld width and penetration. When $f_{\mathrm{L}}$ is higher than $3 \mathrm{~Hz}$, the arc pulsation effect almost disappears, which greatly weakens the advantage of low-frequency pulsation effect. 
Therefore, in order to properly exert the low-frequency pulsation effect, it is recommended to use the lowpulsed frequency of $1-2 \mathrm{~Hz}$ in the DP-VPTIG welding of aluminum alloys.

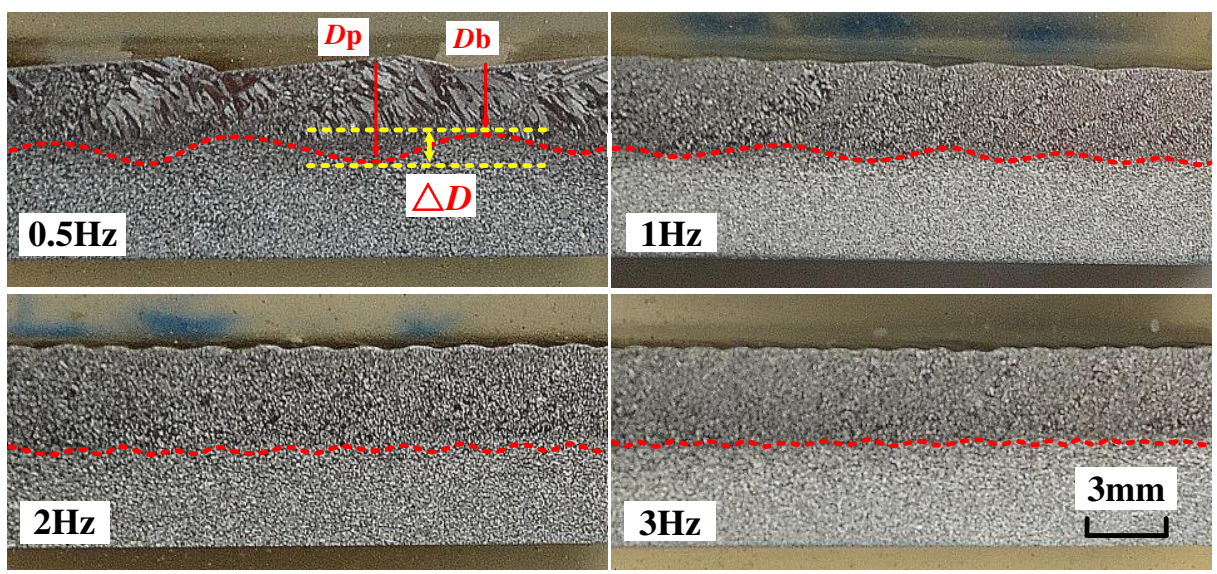

(a) Weld longitudinal section profile

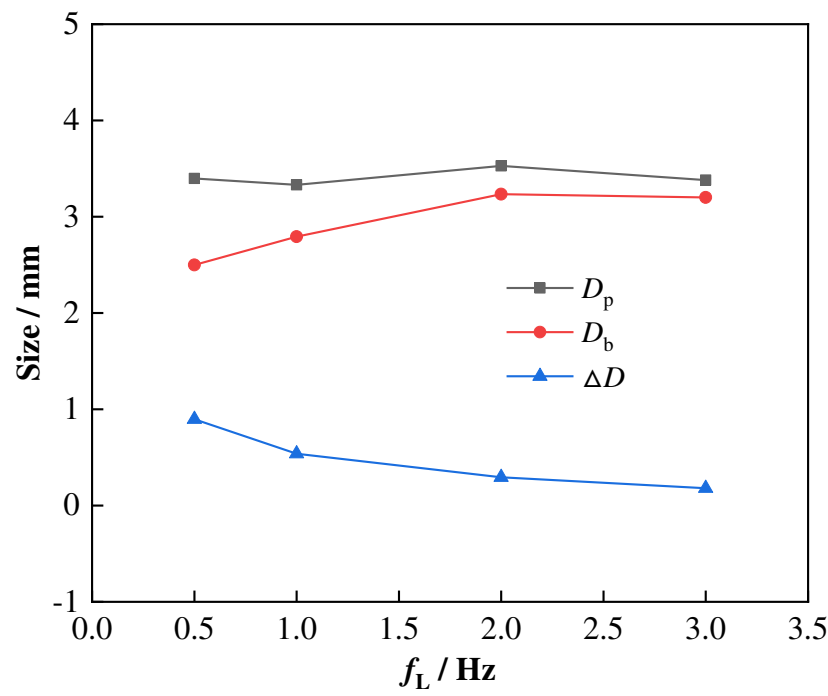

(b) Sizes of $D_{\mathrm{p}}, D_{\mathrm{b}}$ and $\Delta D$

Fig.12 Weld longitudinal section profile, sizes of $D_{\mathrm{p}}, D_{\mathrm{b}}$ and $\Delta D$ versus $f_{\mathrm{L}}$

With the low-frequency pulsation effect of the arc profile, the weld pool fluid could be enhanced and the crystal structure as well as the mechanical properties of the welded joint would thereby be affected. From the macrograph of the weld zone along longitudinal section in Fig.12a, it can be observed that the morphology and distribution of the microstructure varied obviously under different low-pulsed frequencies. The refinement of the grain structure could be found as $f_{\mathrm{L}}$ increased. The microstructure evolution and mechanical properties of the aluminium alloy welded joint produced by DP-VPTIG process need to be further studied.

\section{Conclusions}

The low-pulsed frequency in double-pulsed VPTIG (DP-VPTIG) welding of AA2219 aluminum alloy and its influence on arc profile, weld appearance and penetration characteristics have been investigated. An image processing algorithm was proposed for arc edge extraction and arc feature sizes acquisition. The main conclusions are drawn as follows:

(1) The arc energy equations in low-frequency pulse peak stage $\left(t_{\mathrm{p}}\right)$ and base stage $\left(t_{\mathrm{b}}\right)$ were established 
based on the electrical parameters. The arc profile periodically expanded in $t_{\mathrm{p}}$ and shrunk in $t_{\mathrm{b}}$, resulted from the difference in arc energy of the two stages.

(2) The arc profile pulsation effect, defined by the difference of arc profile between $t_{\mathrm{p}}$ and $t_{\mathrm{b}}$, showed a decreasing trend with the increase of low-pulsed frequency $\left(f_{\mathrm{L}}\right)$. In $t_{\mathrm{p}}$, the arc profile decreased, while in $t_{\mathrm{b}}$, it increased with the increase of $f_{\mathrm{L}}$.

(3) The pulsation effects in weld appearance and penetration exhibited a decreasing trend with $f_{\mathrm{L}}$. They were obvious when $f_{\mathrm{L}}$ was $0.5 \mathrm{~Hz}$, then became weak and tended to disappear as $f_{\mathrm{L}}$ increased above $3 \mathrm{~Hz}$.

(4) The empirical correlations between $f_{\mathrm{L}}$ and the pulsation effects in arc profile, weld appearance and penetration were respectively developed. To properly exert the low-frequency pulsation effect, it is recommended to use the low-pulsed frequency in the range of $1-2 \mathrm{~Hz}$ in the DP-VPTIG welding of aluminum alloys.

\section{Conflict of interest}

The authors declared that they have no conflicts of interest to this work.

\section{Acknowledgements}

This work was supported by the National Natural Science Foundation of China (51675031), Shanghai Natural Science Foundation (19ZR1423300), Beijing Natural Science Foundation (3182020) and the State Key Lab of Advanced Welding and Joining of Harbin Institute of Technology (AWJ-17M-01).

\section{References}

[1] Cong BQ, Ding JL, Williams S. Effect of Arc Mode in Cold Metal Transfer Process on Porosity of Additively Manufactured Al-6.3\% Cu Alloy. Int J Adv Manuf Technol 2013; 76: 1593-1606.

[2] Lin YT, Wang MC, Zhang Y, He YZ, Wang DP. Investigation of microstructure evolution after postweld heat treatment and cryogenic fracture toughness of the weld metal of AA2219. Mater Des 2017; 113: 54-59.

[3] Wu H, Chang YL, Mei Q, Liu D. Research advances in high-energy TIG arc welding. Inter J Adv Manuf Technol 2019; 104: 391-410.

[4] Lu SP, Qin MP, Dong WC. Highly efficient TIG welding of Cr13Ni5Mo martensitic stainless steel. J Mater Process Technol 2013; 213: 229-237.

[5] He LB, Li LM, Hao HW, Wu MS, Zhou RL. Grain refinement and high performance of titanium alloy joint using arc-ultrasonic gas tungsten arc welding. Sci Technol Weld Join 2006; 11(1): 72-74.

[6] Niagaj J. Ways to improve the efficiency of welding stainless steel. Weld Int 2014; 28(1) : 45-53.

[7] Kumar TS, Balasubramanian V, Sanavullah MY. Influences of pulsed current tungsten inert gas welding parameters on the tensile properties of AA 6061 aluminum alloy. Mater Des 2007; 28: 2080-2092.

[8] Yang MX, Zheng H, Qi BJ, Yang Z. Effect of arc behavior on Ti-6Al-4V welds during high frequency pulsed arc welding. J Mater Process Technol 2017; 243: 9-15.

[9] Fang YX, Liu ZM, Cui SL, Zhang Y, Qiu JY, Luo Z. Improving Q345 weld microstructure and mechanical properties with high frequency current arc in keyhole mode TIG welding. J Mater Proc Technol 2017; $250: 280-288$.

[10] Yang Z, Qi BJ, Cong BQ, Liu FJ, Yang MX. Microstructure, tensile properties of Ti-6Al-4V by ultra 
high pulsefrequency GTAW with low duty cycle. J Mater Proc Technol 2015; 216: 37-47.

[11] Cui SL, Liu ZM, Fang YX, Luo Z, Sunusi MM, Yi S. Keyhole process in K-TIG welding on $4 \mathrm{~mm}$ thick 304 stainless steel. J Mater Proc Technol 2017; 243: 217-228.

[12] Wang YP, Qi BJ, Cong BQ, Yang MX, Liu FJ. Arc characteristics in double-pulsed VP-GTAW for aluminum alloy. J Mater Process Technol 2017; 249: 89-95.

[13] Wang YP, Qi BJ, Cong BQ, Yang MX, Zhu MJ, Lin SB. Keyhole welding of AA2219 aluminum alloy with double-pulsed variable polarity gas tungsten arc welding, J Manuf Process 2018; 34: 179-186.

[14] Wang YP, Cong BQ, Qi BJ, Yang MX, Lin SB. Process characteristics and properties of AA2219 aluminum alloy welded by double pulsed VPTIG welding. J Mater Process Technol 2019; 266: 255-263.

[15] Liu A, Tang X, Lu F. Arc profile characteristics of Al alloy in double-pulsed GMAW. Int J Adv Manuf Technol 2013; 65: 1-7. 


\title{
Influence of low-pulsed frequency on arc profile and weld formation
} characteristics in double-pulsed VPTIG welding of aluminium alloys

\author{
Wang, Yipeng
}

Elsevier

Wang Y, Cong B, Qi B, et al., (2020) Influence of low-pulsed frequency on arc profile and weld formation characteristics in double-pulsed VPTIG welding of aluminium alloys. Journal of Manufacturing Processes, Volume 58, October 2020, pp. 1211-1220

https://doi.org/10.1016/j.jmapro.2020.09.025

Downloaded from Cranfield Library Services E-Repository 